\title{
APPLICATION OF STRUCTURE FROM MORTION IN JAPANESE ARCHAEOLOGY
}

\author{
Akihiro Kaneda $^{\text {A, } * \text {, Yama Ahmad Nawabi }}{ }^{\text {B }}$, Hiroshi Yamaguchi ${ }^{\mathrm{C}}$. \\ A Nara National Research Institute for Cultural Properties, Center for Archaeological Operation, 247-1 Saki-cho Nara-shi, Japan - \\ akaneda@nabunken.go.jp \\ ${ }^{\mathrm{B}}$ Waseda University \\ ${ }^{\mathrm{C}}$ Ritsumeikan University
}

KEY WORDS: Structure from Motion, SfM, Computer Vision, Archaeological Documentation, UAV

\begin{abstract}
:
In Japan, archaeological excavations carry out over fifty thousand times per year. Nowadays, archaeological data is accumulated day by day. To record these documentation about archaeological data, it is desirable to the documentation of their shape in 3-dimensional form. Structure from Motion (SfM) is the one of the cost effective method to record the 3D documentation. This paper introduces application of SfM technology to examine the validity of an archaeological documentation in Japanese archaeology in recent year.

Whenever, a complicated form finding has to be recorded at an archaeological excavation. It often requires a long time to create by a traditional manual drawing. For example, a well made of reuse roof tiles, garden stones and stone chamber. By using SfM, the time spent working at the archaeological site was greatly reduced. And many platforms to take an image at the variety of archaeological site's condition, like a small UAV (Unmanned Aerial Vehicle) are tested using for wider area recording. These methods are used in disaster stricken areas in East Japan.
\end{abstract}

\section{INTRODUCTION}

Basically, Archaeological materials are solid objects, so it is desirable to the documentation of their shape in 3-dimensional form. However, it was difficult to this method which demanded high-cost and technic. Therefore, archaeological documentation used 2-dimensional line drawings has been mainly used as an alternative method, and the accumulation of the results have been the base materials supporting archaeological research. This method of documentation has been independently refined in Japan and an original detailed format for measuring has been established for materials with complex shape.

The Nara National Research Institute for Cultural Properties, Japan (Nabunken) while working on a foundational method for measuring archaeological documentation in $2 \mathrm{D}$, has been carrying out 3D measurement technology, starting with Photogrammetry, for more than 60 years. However, progress in the popularization of 3D measurement methods based on their development and improvement in recent years is considered to lead to a method of recording that has originally been considered ideal, which will greatly change the current situation.

Obviously, it is difficult to ignore the accumulation of existing documentations and transition to 3D measuring, given the current circumstances. While it is necessary at this point to give consideration to continuity and compatibility with records as an outcome, it is also necessary to positively investigate and promote an effective method of measuring.

As methods of recording 3-dimensional shapes using computer vision technology, Structure from Motion (SfM) and Multi View Stereo (MVS) technologies that use image data have borne fruit in recent years (Lo Brutto and Meli 2012). The costs of deploying these technologies, from a technical and economic standpoint, is lower than measurement technologies such as 3D laser scanners, and, when looking at the current state of cultural records (Kaneda2009), they are considered to be effective methods.
Researchers believe that their use should be promoted and have both conducted tests and put them into practice.

In this study, we will report on several examples where we put these methods into practice in Nara Prefecture, located in the central area of Japan, and describe their effectiveness and limitations.

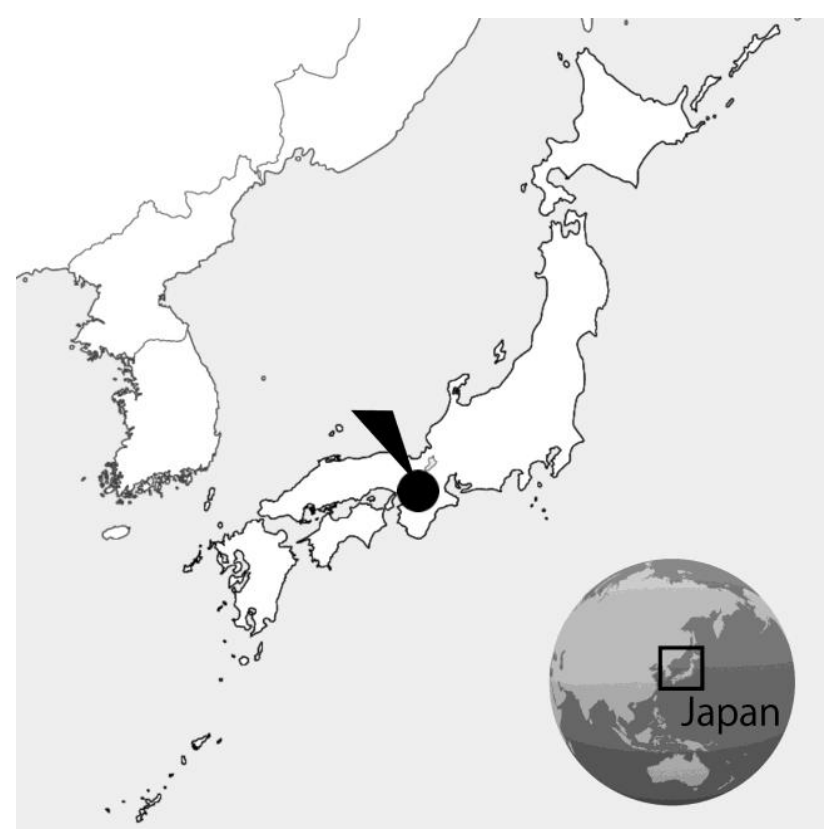

Figure 1. Location of the Nara Prefecture in JAPAN.

*corresponding author 


\section{AT ARCHAEOLOGICAL SITES}

\subsection{A water well in Saidaiji Temple}

Saidaiji is a large temple constructed during the Nara Period in the $8^{\text {th }}$ Century. A water well has been excavated from one corner of the corridor in the temple that was created in a flat circular shape using reuse roof tiles.

It nearly always takes a long time of manual work to record these targets, which takes several days in many cases. By using SfM, however, the time spent working at the site was greatly reduced to 15 minutes.

The results were swiftly fed back to the site, which made it possible to confirm detailed sections during the period of the survey. Furthermore, in terms of accuracy, the authors attempted to compare the SfM result and the actual length.

The SfM result calculates the distance between any two points on the software. The actual length measured by a steel tape in the excavated site.

As a result, the accuracy in this case is under $1 \mathrm{~cm}$ (horizon) and $2 \mathrm{~cm}$ (Vertical). It is measure and achieve the same level of accuracy as with manual hand drawing.

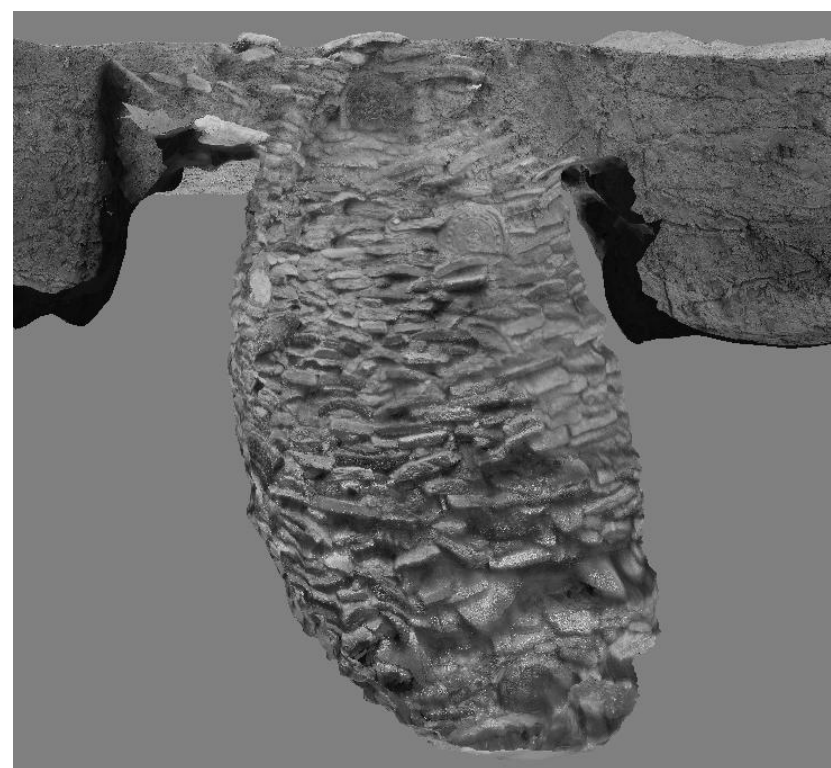

Figure 2. 3D model of the water well in Saidaiji Temple.

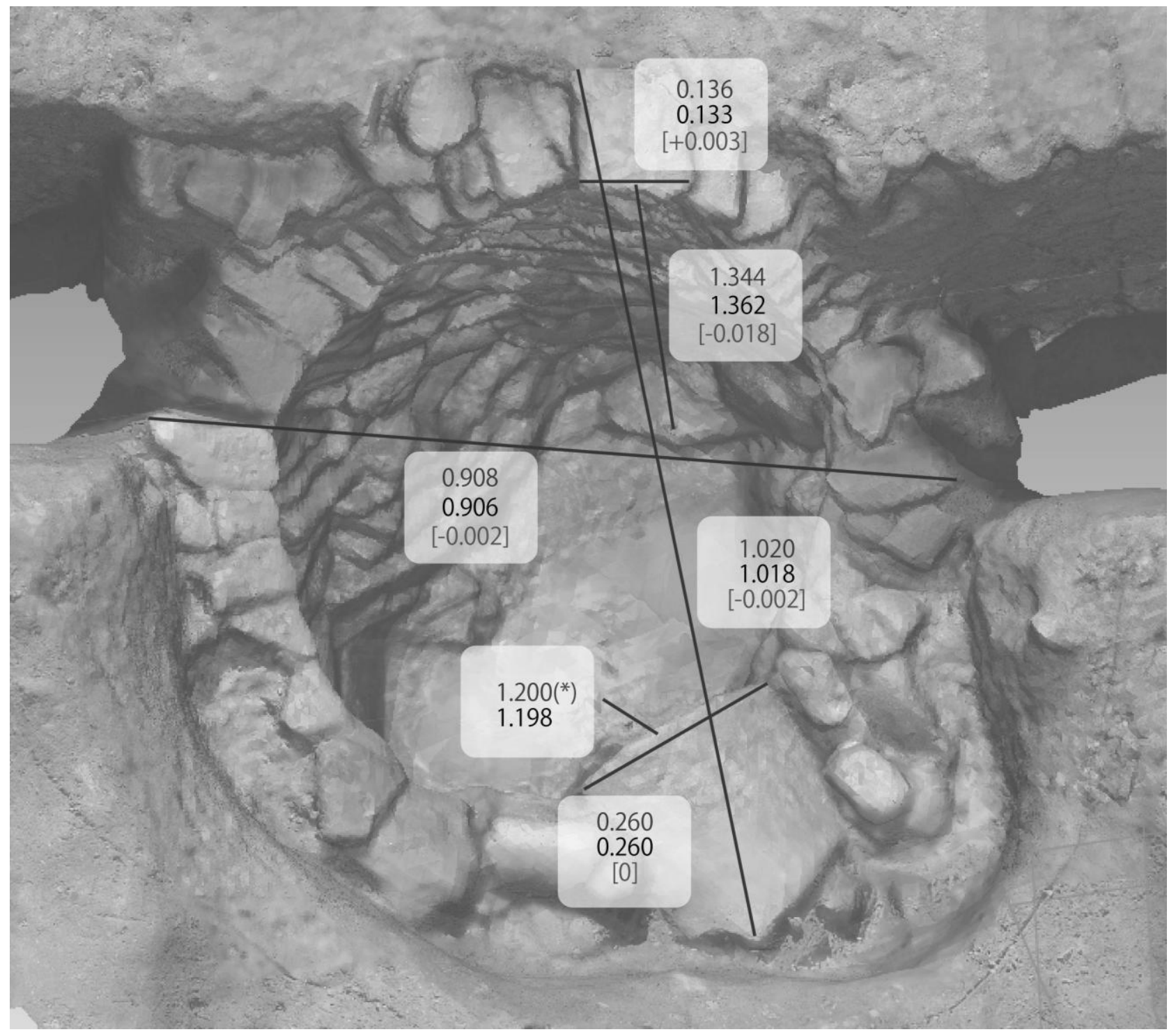

Figure 3. A comparison of actual length and SfM model. 


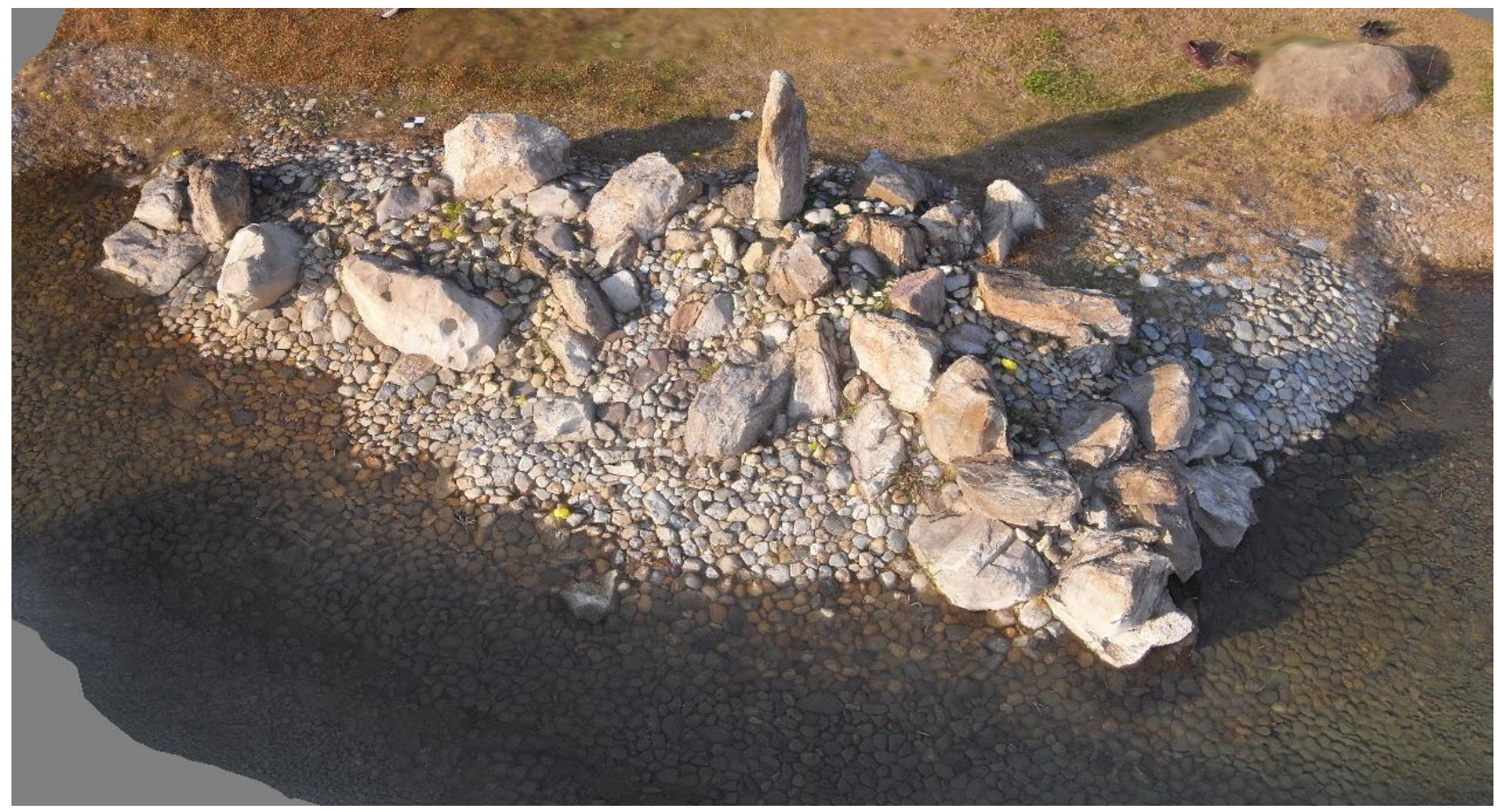

Figure 4. 3D model of the garden rocks at the Toin Garden bySfM.

\subsection{Heijyo-kyu Palace Toin (east palace) Garden}

Heijyo-kyo was the capital of Japan in the $8^{\text {th }}$ Century. It locate in Nara-city, JAPAN. It was inscription on World Heritage Site in 1998. Heijyo-kyu was a central palace, which located in the northern-center part of the Heijokyo.

The east side of this palace used as a garden in the second half of the $8^{\text {th }}$ Century. According to ancient document, the ShokuNihongi written in the $9^{\text {th }}$ century, this garden was called Toin (east palace). It was discovered as the result of an archaeological excavation that garden rocks remain in this garden. Currently, the garden has been rearranged based on the results of the excavation and made accessible to the general public.

The shape of the stone bed formed by the combination of these stones takes time to measure, and measurement has been traditionally performed using photographic measurement and 3D laser scanners.

In this study, it used two ways to take photos by a UAV and a long pole. On this occasion, the same results were successfully achieved through SfM measurement.

\subsection{Stone Chamber in burial mounds}

In Japan from the $5^{\text {th }}$ to the $7^{\text {th }}$ Centuries, horizontal stone chambers were often used as tomb burial spots. These stone chambers needed to have increased rigidity on a structural level, and many were of a sloped shape towards the top of the wall. As a result, there is a traditional method in which measurement takes place by setting the horizontal and perpendicular projected surfaces to create the measurement plans and setting reference lines based on this. This method takes a lot of effort and does not produce satisfactory results from an accuracy point of view.

These measurements were attempted using SfM and highly accurate results could be obtained in a short amount of time. A lot of care needed to be taken to record sections where photos are taken at the entrance to the Bentenzuka Tumulus. When measuring the stone chamber, technical observation not only of the stone shape but also of the processed state of the surface is required, but observation with the relief image enables clear observation of the state of the stone surface.

The Iwayayama Tumulus is wider and photographing it was simple compared to the Bentenzuka Tumulus, but processing the modeling using SfM was more difficult than expected. The cause of this was that the extraction of the required feature values was insufficient, due to a lack of photographs, the stone materials used for the target stone chamber being large and it being processed in a smooth way.

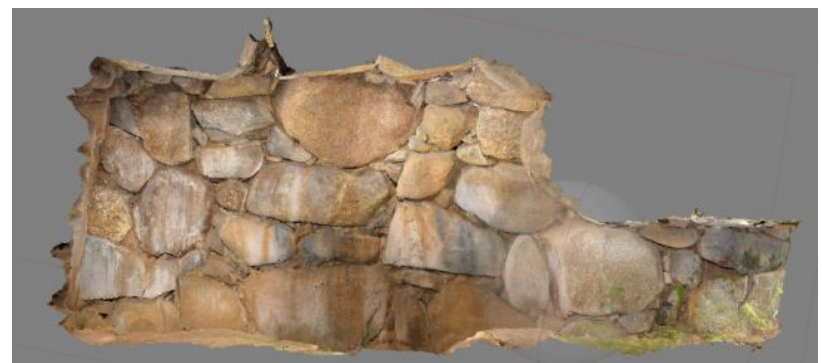

Figure 5. 3D model of the stone chamber in the Bentenzuka burial mound by SfM (Textured).

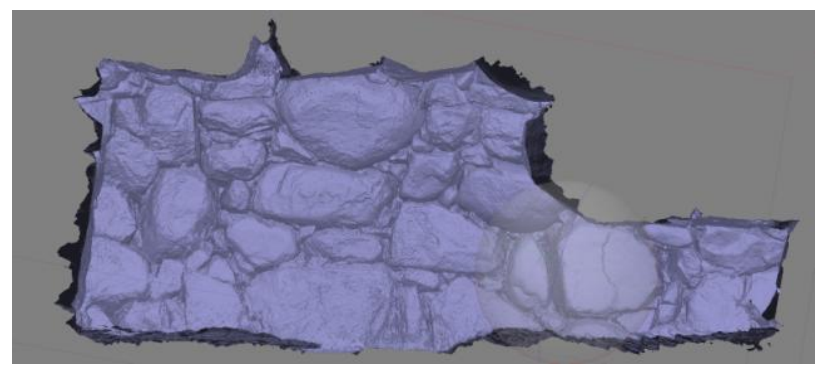

Figure 6. 3D model of the stone chamber in the Bentenzuka burial mound by SfM (Solid). 


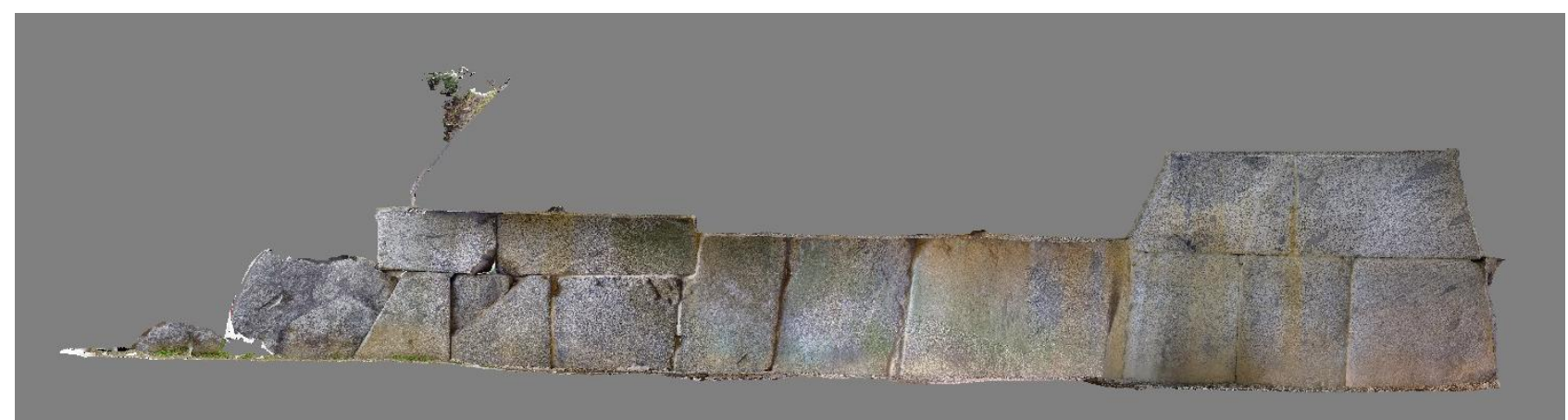

Figure 7. 3D model of the stone chamber in the Bentenzuka burial mound by SfM (Textured).

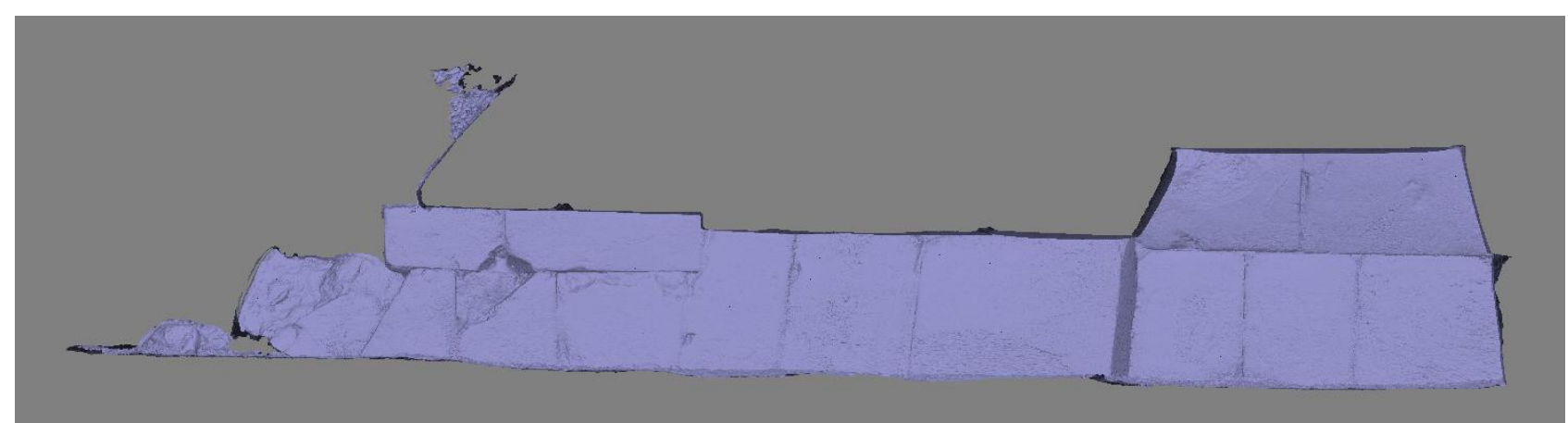

Figure 8. 3D model of the stone chamber in the Bentenzuka burial mound by SfM (Solid).

\section{UAV PLATHOME}

Currently, carbon fiber poles and free platforms are used to obtain the images that are to be used in SfM. By performing remote photography using these compact mirror-less single lens reflexes, it is nearly always possible to capture relics and remains.

However, when recording over a wider area, UAV (Unmanned Aerial Vehicle) is a device that has recently garnered much attention (Neitzel and Klonowski 2011, Uchiyama et al. 2013) .

At the Nabunken, Authors are capturing record photographs and videos of the environment surrounding the relics using compact UAV and conducting deciphering experiments for relics using multi-band cameras. Here, we will introduce 3D measurement tests using UAV and SfM.

In terms of UAV, we have also seen the introduction of largescale devices and there use is expected to increase further in the future, but due to issues related to securing the deployment costs and ensuring safety, research has thus far focused on operations using small equipment.

The payload of the equipment used was limited to several hundred grams. For this reason, previous studies often involved examples of measurement using action cams or small-sized compact cameras.

In order to take measurements using UAV in the Toin-teien (East Temple Gardens), the smallest class of mirror-less single lens reflex camera with a single focus lens attached was used in order to obtain more detailed images. Ideally, it should be equipped with an FPV (First Person View) system or multi-axis gimbal for monitoring, but in order to keep down its weight, the camera was fixed using a rubber and plastic belt. Since the usable radio wave bands are highly restricted by law in Japan and it is difficult to wirelessly manage support for the shutter, the camera was set to capture image continuously at 1 -second intervals.

As a result, it was possible to obtain the measurement images much faster than with poles. On the other hand, since there were only images from above and no images from a diagonal direction or horizontal direction, there were some problem in capturing images of narrow, long stones stand from the ground in terms of modeling the side of the stones, compared to the results obtainted from images captured using poles or tripods.

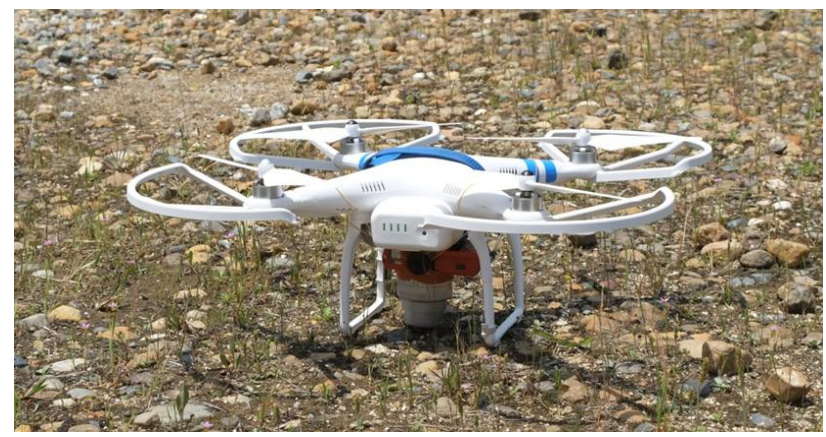

Figure 9. Mounting camera to UAV.

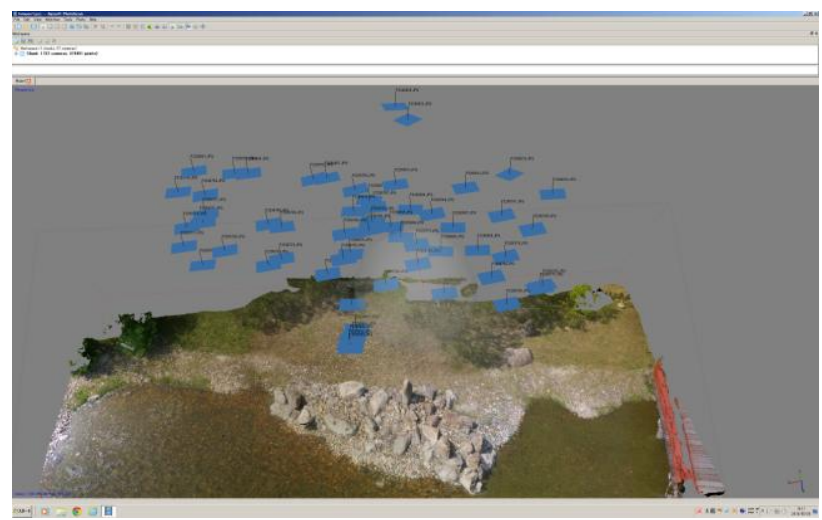

Figure 10. Camera position and reconstructed model from UAV image. 


\section{USE IN DISASTER-STRICKEN AREAS}

The Great East Japan earthquake that occurred on March 11, 2011 was an unprecedented tragedy in which buildings were destroyed as a result of the earthquake, houses were washed away by the tsunami, and there was a huge number of casualties in areas on the side of the Pacific. The loss of functionality and explosion at the nuclear power plant is still causing great hardship to a large number of people.

Development is currently in progress through the recovery of these regions, from the perspective of reducing and preventing disaster through the revival of those areas and use of their experience. Cultural properties have been accepted by people in the community as a symbol of recovery from repeated disasters. However, there is an urgent need for a recovery as soon as possible, and it is necessary to develop swifter investigative methods at each stage of the survey in excavational surveys that accompany recovery.

For this reason, we have conducted 3D measurement of relics with complex shapes using laser scanners and SfM, for our survey in Fukushima Prefecture situated in the northeastern part of Japan.

\section{SUMMARY}

There is a wide variety of software for 3D measurement using SfM, from commercial to FOSS use. Based on the results of comparison tests, commercial software is mainly used at present. However, the establishment and popularization of work procedures that employ means with lower costs of introduction is essential in order for its use to be promoted further in the future.

Moving forward, we need to investigate low-cost means such as FOSS, pursue methods that can be used by researchers who necessitate such methods, and consider the possibilities and limitations through their practical application.

Kaneda, A., 2009 Application of a Low Cost Laser Scanner for Archaeology in JAPAN. XXII CIPA Symposium - Kyoto, JAPAN - 11 October - 15 October 2009 Proceedings. http://cipa.icomos.org/fileadmin/template/doc/KYOTO/35.pdf

Neitzel, F., Klonowski, J. 2011 Mobile 3D Mapping with A Lo w-Cost UAV System, International Archive of the Photogramm etry. Remote Sensing Spatial Information Science., XXXVIII-1/ C22, http://www.int-arch-photogramm-remote-sens-spatial-inf-s ci.net/XXXVIII-1-C22/25/2011/isprsarchives-XXXVIII-1-C2225-2011.pdf.

Lo Brutto M., Meli, P., 2012. Computer vision tools for 3D mo delling in archaeology, International Journal of Heritage in the Digital Era, Volume 1, Supplement, pp 1-6.

Uchiyama, S., Inoue, H., Suzuki, H. 2013 Approaches for Reconstructing a Three-dimensional Model by SfM to Utilize and Apply this Model for Research on Natural Disasters. Report of the National Research Institute for Earth Science and Disaster Prevention, No. 81., pp.37-60. (Printed in Japanese).

Andrews,D.P., Bedford, J.and Brya, P.G., 2013 A comparison of laser scanning and structure from motion as applied to the great barn at Harmondsworth, UK. International Archives of the Photogrammetry, Remote Sensing and Spatial Information Sciences, Volume XL5/W2, 2013 XXIV International CIPA Symposium. 